\title{
Characterization of Lactobacillus plantarum Lp27 isolated from Tibetan kefir grains: A potential probiotic bacterium with cholesterol-lowering effects
}

\author{
Ying Huang, Fei Wu, Xiaojun Wang, Yujie Sui, Longfei Yang, and Jinfeng Wang ${ }^{1}$ \\ Central Research Laboratory, Second Hospital of Jilin University, Changchun 130041, People's Republic of China
}

\begin{abstract}
Lactobacillus plantarum Lp27 was isolated from Tibetan kefir grains. The Lp27 isolate survived a 3-h incubation at $\mathrm{pH} 2.0$ and grew normally in $0.3 \%$ oxgall. In addition, the Lp27 isolate exhibited an adhesion ratio of $9.5 \pm 2.5 \%$ with Caco- 2 cells. Antibiotic susceptibility tests indicated that the Lp27 isolate was sensitive to gentamicin, tetracycline, erythromycin, and chloramphenicol, and was resistant to vancomycin with a minimum inhibitory value of $23 \mu \mathrm{g} / \mathrm{mL}$. The Lp27 isolate inhibited cholesterol absorption through downregulation of Niemann-Pick C1-like 1 (NPC1L1) expression in Caco-2 cells. The Lp27 isolate was fed to hypercholesterolemic rats at a dose of $10^{9} \mathrm{cfu} / \mathrm{d}$ for 4 wk. The Lp27 feeding significantly lowered serum total cholesterol, low-density lipoprotein cholesterol, and triglycerides concentrations, but no change was observed in the serum high-density lipoprotein cholesterol concentrations. In addition, liver total cholesterol and triglycerides were decreased in the Lp27-fed group. The expression of NPC1L1 in the duodenum and jejunum was significantly decreased following Lp27 feeding. These results indicate that Lp27 might be an effective cholesterol-lowering probiotic and a possible mechanism for the cholesterol-reducing effects of probiotics.
\end{abstract}

Key words: Lactobacillus plantarum Lp27, Tibetan kefir grains, cholesterol reduction, Niemann-Pick C1like 1

\section{INTRODUCTION}

Hypercholesterolemia and elevated concentrations of dietary cholesterol are both associated with an increased risk of cardiovascular disease. A reduction as small as $1 \%$ in serum cholesterol concentrations has been shown to decrease the risk of coronary heart disease in human subjects by 2 to $3 \%$ (Manson et al., 1992). Endogenously synthesized cholesterol, the absorption of dietary cholesterol, and the reabsorption of biliary cholesterol

Received November 12, 2012

Accepted January 25, 2013.

${ }^{1}$ Corresponding author: jinfengwang2005@hotmail.com in the small intestine contribute to the regulation of plasma cholesterol concentrations (Wilson and Rudel, 1994). Moreover, reducing the intestinal absorption of dietary and biliary cholesterol can decrease plasma cholesterol concentrations (Temel et al., 2007, 2010). The beneficial effects of lactic acid bacteria (LAB) in the intestinal tract and the potential of particular strains as probiotics have been reported in numerous studies (Franz et al., 2010). Specifically, the potential of probiotic strains to lower the cholesterol level is gaining increased attention (Liong and Shah 2005, 2006; Ooi and Liong, 2010). However, the mechanism of the hypocholesterolemic effects of probiotics has not been fully elucidated.

Niemann-Pick C1-like 1 (NPC1L1) has been identified as a critical protein for intestinal cholesterol absorption; NPC1L1 is highly expressed in the small intestine, especially at the surface of enterocytes (Altmann et al., 2004). Mice deficient in NPC1L1 show dramatic reductions in dietary cholesterol absorption (Altmann et al., 2004) and are completely resistant to both diet-induced hypercholesterolemia and apolipoprotein E deficiencyinduced atherosclerosis (Davis et al., 2004, 2007). In rats, the expression level of NPC1L1 along the length of the small intestine has been correlated with the efficiency of cholesterol absorption, with the highest expression found in the proximal intestine (duodenum and jejunum) and the lowest expression found in the distal intestine (ileum; Altmann et al., 2004).

Tibetan kefir grain (TK) is a natural starter for fermented milk used in Tibet, China, which contains LAB, acetic acid bacteria, and yeasts (Farnworth and Mainville, 2003). Tibetan kefir can be considered a probiotic resource because it can provide a variety of health benefits in addition to its nutritional status (Urdaneta et al., 2007). Many studies that have investigated the biological activities of TK identified antimicrobial, immunomodulating, anti-inflammatory, and hypocholesterolemic activities (Diniz et al., 2003; Vinderola et al., 2005; Liu et al., 2006; Silva et al., 2009). Various LAB present in TK have been isolated and include Lactobacillus acidophilus (Angulo et al., 1993), Lactobacillus plantarum (Garrote et al., 2001), and Lactobacillus kefiranofaciens (Chen et al., 2012). 
In the present study, we identified and characterized a new strain of Lactobacillus from TK and evaluated its probiotic properties, including acid and bile salt tolerance, Caco-2 cell binding, and antibiotic susceptibility properties, in addition to hypocholesterolemic activities. The in vitro uptake of cholesterol and the in vivo effects of the Lactobacillus strain on serum cholesterol levels in rats were determined. The mechanisms by which the strain removed cholesterol in vitro and in vivo were also analyzed. Our goal is to develop a new LAB that can serve as a probiotic to lower cholesterol levels in humans.

\section{MATERIALS AND METHODS}

\section{TK}

The TK was collected from Tibet, China, and was evaluated. The grains were cultured in sterile $10 \%$ reconstituted skim milk at $20^{\circ} \mathrm{C}$ for $20 \mathrm{~h}$. Tibetan kefir grains were then filtered and stored at $4^{\circ} \mathrm{C}$.

\section{Isolation of LAB and Cultivation from TK}

The TK was recovered from the mother culture after reaching the fermentative end-point. Ten grams of TK was suspended in $90 \mathrm{~g}$ of sterile saline buffer $(0.85 \%)$ and homogenized with a Stomacher (Laboratory Blender Stomacher 400, Seward, UK) for $20 \mathrm{~min}$. Serial dilutions of the suspended samples were used for microbial enumerations and isolation on de Man, Rogosa, Sharpe (MRS) agar (Difco, Detroit, MI) under both aerobic and anaerobic conditions and on LM17 agar [M17 agar (Difco) with 0.5\% (wt/wt) lactose (Sigma, St. Louis, MO)] under aerobiosis. In addition, $200 \mu \mathrm{g} /$ $\mathrm{ml}$ of cycloheximide (Sigma) was added to both the MRS and LM17 agars to inhibit the growth of yeasts. The plates were incubated at $30^{\circ} \mathrm{C}$ for $7 \mathrm{~d}$. After $7 \mathrm{~d}$, yellowish colonies typical of lactobacilli were selected for morphological examination under a microscope. Pour plating was also performed with dilutions of $1: 10^{7}$ and $1: 10^{8}$, and the submerged colonies were selected for morphological examination using Gram staining. The putative Lactobacillus isolates were further subjected to catalase testing and molecular typing methods. Standard bacterial cultures, namely Lb. acidophilus ATCC 4356 and $L b$. plantarum ATCC 8014, were obtained from ATCC (Rockville, MD).

\section{Identification of Lactobacillus Isolates by PCR}

Genomic DNA was extracted from cultures grown at $37^{\circ} \mathrm{C}$ for 16 to $18 \mathrm{~h}$ in MRS broth using the protocol described by Pospiech and Neumann (1995). A PCR reaction was performed in a total volume of $50 \mu \mathrm{L}$ that included $0.5 \mu M$ of each primer, 1.25 units of Taq DNA polymerase, $20 \mathrm{ng}$ of DNA template, and $200 \mu \mathrm{M}$ of each deoxynucleotide triphosphates and PCR buffer containing Tris- $\mathrm{HCl}, \mathrm{KCl}$, and $\mathrm{MgCl}_{2}$. The amplification conditions were as follows: initial denaturation at $94^{\circ} \mathrm{C}$ for $5 \mathrm{~min}$, followed by 35 cycles of denaturation at $95^{\circ} \mathrm{C}$ for $30 \mathrm{~s}$, annealing for $30 \mathrm{~s}$ at $55^{\circ} \mathrm{C}$, and a final extension of $10 \mathrm{~min}$ at $72^{\circ} \mathrm{C}$. The PCR-amplified DNA fragments were resolved by agarose gel electrophoresis and stained with ethidium bromide $(0.5 \mathrm{mg} / \mathrm{mL})$ followed by visualization under UV light.

Genus-specific PCR assays were performed using the forward primer LbLMA-1 (5'-CTCAAAACTAAAGTTTC-3') and the reverse primer R-161 (5'-CTTGTACACACCGCCCGTTCA-3'; Dubernet et al., 2002 ). Sequencing of the $16 \mathrm{~S}$ ribosomal RNA genes was performed to validate the phenotypic characterization of the Lactobacillus strains. The $16 \mathrm{~S}$ ribosomal DNA of the selected strains were amplified by PCR using 2 universal primers: $27 \mathrm{f}$ and 1492r (Weisburg et al., 1991). The PCR products obtained were cloned, sequenced, and then compared using the NCBI BLAST sequence database (http://www.ncbi.nlm.nih.gov/nuccore/JQ236617.1) to identify the species of each strain. Sequencing was performed by Bioasia Co. (Shanghai, China).

\section{Acid Tolerance}

The MRS broth was used to simulate the acidic conditions of the gut and was adjusted to different $\mathrm{pH}$ values (1.0, 2.0, and 3.0) with $1.0 \mathrm{~N} \mathrm{HCl}$; broth was adjusted to neutral $\mathrm{pH}$ (7.0) to serve as a control. Tubes of broth adjusted to the different $\mathrm{pH}$ values were inoculated (at $10^{9} \mathrm{cfu} / \mathrm{mL}$ ) with cultures of lactobacilli grown overnight and incubated at $37^{\circ} \mathrm{C}$ for 24 to $48 \mathrm{~h}$. One milliliter of culture was immediately taken from each tube $(0 \mathrm{~h})$, and 10 -fold serial dilutions were prepared in $0.1 \%$ peptone water; pour plating was performed using MRS agar. Similarly, $1 \mathrm{~mL}$ of culture was taken from each tube after intervals of $1,2,3$, and $4 \mathrm{~h}$, followed by plating. The plates were incubated at $37^{\circ} \mathrm{C}$ for 24 to 48 $\mathrm{h}$ and the colony-forming units were counted.

\section{Bile Salt Tolerance}

The MRS broth supplemented with 0.2 and $0.3 \%$ (wt/ vol) oxgall was used to mimic the approximate levels of bile salts in the intestinal tract; MRS broth without bile salt was used as a control. A fresh overnight culture of Lp27 was inoculated at a final concentration of $1 \%$ (vol/vol) into each media, incubated at $37^{\circ} \mathrm{C}$ for $18 \mathrm{~h}$, and monitored for growth hourly by spectrophotometry 
at $620 \mathrm{~nm}$. The time required to increase the absorbance at $620 \mathrm{~nm}$ by 0.3 units was measured in MRS broth with and without oxgall. The difference in time (h) between the 2 culture media was considered to be the lag time during which the bile salt tolerance effect was expressed.

\section{Caco-2 Cell Adhesion Assay}

The adhesion capability of the isolates was assayed according to the method described by Jacobsen et al. (1999). Initially, $1 \times 10^{5}$ Caco- 2 cells were seeded into each well of a 6-well tissue culture plate. Dulbecco's modified Eagle's minimal essential medium (DMEM) supplemented with $10 \%$ (vol/vol) heat-inactivated (30 min, $56^{\circ} \mathrm{C}$ ) fetal bovine serum, $100 \mathrm{U} / \mathrm{mL}$ of penicillin, and $100 \mathrm{mg} / \mathrm{mL}$ of streptomycin was used for culturing. The medium was replaced with fresh medium every other day and an adhesion assay was performed after $20 \mathrm{~d}$ postconfluency. The cells were then washed twice with $3 \mathrm{~mL}$ phosphate-buffered saline ( $\mathrm{pH}$ 7.4). Two milliliters of DMEM without serum or antibiotics was added to each well and incubated at $37^{\circ} \mathrm{C}$ for $30 \mathrm{~min}$. Approximately $10^{9} \mathrm{cfu} / \mathrm{mL}$ of bacterial culture was suspended in $1 \mathrm{~mL}$ of DMEM (without serum or antibiotics) and added to the different wells. The plate was incubated at $37^{\circ} \mathrm{C}$ for $2 \mathrm{~h}$ in a $5 \% \mathrm{CO}_{2}, 95 \%$ air atmosphere. The monolayer was washed with sterile PBS and the cells were detached by trypsinization. One milliliter of $0.25 \%$ trypsin-EDTA solution (Sigma) was added to each well of a 6 -well plate, the plate was then incubated for $15 \mathrm{~min}$ at room temperature. The cell suspension was plated onto MRS agar by serial dilution to determine the number of adherent bacterial cells. The plate was incubated for 24 to $48 \mathrm{~h}$ at $37^{\circ} \mathrm{C}$ and the colonies were counted. The number of bacterial cells initially added to each well of the 6-well plates were also counted by serial dilution and plating onto MRS agar. The results of the adhesion assay were expressed as the adhesion percentage (i.e., the ratio between adherent bacteria and added bacteria per well). Caco-2 cells of the same passage were used for 3 independent experiments $(\mathrm{n}=3)$ with 2 replicates in each experiment.

\section{Antibiotic Susceptibility Testing}

The MIC of gentamicin, tetracycline, erythromycin, chloramphenicol, and vancomycin (Sigma) was determined for Lp27 using the procedure as previously described (Rossetti et al., 2009). According to FEEDAP (2005), MIC breakpoint values for gentamicin, tetracycline, erythromycin, chloramphenicol, and vancomycin were $8,8,4,4$, and $4 \mu \mathrm{g} / \mathrm{mL}$, respectively.

\section{Bacteria, Cell Lines, and Coculture}

The reference strains Lactobacillus plantarum ATCC 8014 and Lactobacillus acidophilus ATCC 4356 were obtained from ATCC. For all experiments, Lp27 was precultured for 6 to $8 \mathrm{~h}$ at $37^{\circ} \mathrm{C}$ on a rotating platform $(225 \mathrm{rpm})$. Precultures were then added to prewarmed MRS medium (dilution 1:20). The cultures were cultivated overnight before use. One $\mathrm{OD}_{600 \mathrm{~nm}}$ (optical density at $600 \mathrm{~nm}$ ) of bacteria culture was equivalent to $1 \times 10^{8} \mathrm{Lp} 27 / \mathrm{mL}$. The required amount of $\mathrm{Lp} 27$ was resuspended in an appropriate volume of the respective prewarmed medium without antibiotics. The coculture was prepared by washing Caco-2 cells with warm PBS. The cells were incubated with Lp27 or with medium alone. The experiment was terminated by thoroughly washing the plates with ice-cold PBS.

\section{Cholesterol Uptake Assay}

Caco-2 cells were seeded onto 6 -well plates at a density of $1 \times 10^{5}$ cells/well were incubated with Lp27, Lb. plantarum ATCC 8014 or Lb. acidophilus ATCC 4356 for 6 h. For comparison, nontreated Caco-2 cells were also included. One hour before harvesting the cells, $0.15 \mathrm{~mL}$ of a micellar solution containing $6.6 \mathrm{mM}$ sodium taurocholate, $74,000 \mathrm{~Bq}(2 \mathrm{mCi})\left[{ }^{3} \mathrm{H}\right]$ cholesterol, $1 \mathrm{~m} M$ oleic acid, $0.5 \mathrm{~m} M$ monoolein, $0.1 \mathrm{~m} M$ unlabeled cholesterol, and $0.6 \mathrm{mM}$ phosphatidylcholine was added to the Caco-2 cells. At the end of the incubation, the unincorporated, radiolabelled cholesterol was removed by washing the cells 4 times with $1.5 \mathrm{~mL}$ of cold DMEM. The cellular lipids were extracted with 1.5 $\mathrm{mL}$ of hexane:isopropyl alcohol:water (3:2:0.1, vol/vol/ vol). The radioactivity in the cellular lipid extract was estimated by counting with a Packard liquid scintillation counter.

\section{Animal Feeding and Grouping}

Animal experiments were conducted in compliance with the Guide for Care and Use of Laboratory Animals from the National Institutes of Health (Yin et al., 2010). Twenty male Sprague-Dawley rats (4 wk of age) were obtained from the National Animal Breeding and Research Center, Beijing, China. The rats were fed a commercial chow (Kangqiao Inc., Beijing, China), which included $32 \%$ protein, $5 \%$ fat, $2 \%$ fiber, $1.8 \%$ $\mathrm{Ca}, 1.2 \% \mathrm{P}$, and $59 \% \mathrm{~N}$-free extract for 1 wk. Rats were individually housed in metal cages at a controlled temperature $\left(23 \pm 2^{\circ} \mathrm{C}\right)$ and humidity $(55 \pm 6 \%)$ under a 12-h light-dark cycle. After this adaptation period, rats were divided into 2 groups consisting of 10 rats each; the initial average BW were similar between the 
2 groups. Each group was assigned one of the following diet regimens: (1) high-cholesterol diet (HC diet group) or (2) high-cholesterol diet $+L b$. plantarum Lp27 (HC Lp27 group). The high-cholesterol diet contained 1\% (wt/wt) cholesterol, $10 \%$ lard, $5 \%$ sucrose, $0.3 \%$ sodium cholate, $0.2 \%$ propylthiouracil, and $78.5 \%$ commercial chow (Aoboxing Biotech Co. Ltd., Beijing, China). Each day of the study period, the HC Lp27 group received $2 \mathrm{~mL}\left(10^{9} \mathrm{cfu} / \mathrm{mL}\right)$ of an Lb. plantarum Lp27 solution intragastrically. The $\mathrm{HC}$ diet group received an equivalent amount of normal saline. The rats were fed for $4 \mathrm{wk}$, during which time BW and food intake were recorded daily. After the feeding period, the rats were fasted overnight and used for subsequent testing.

\section{Assay for Serum Lipids}

Blood samples were collected from the tail veins of the rats under diethyl ether anesthesia on d $0,7,14,21$, and 28. Approximately $1 \mathrm{~mL}$ of blood was taken from each rat, transferred to sterile tubes and kept on ice for $30 \mathrm{~min}$. The tubes were then centrifuged at 2,000 $\times$ $g$ for $20 \mathrm{~min}$ at $4^{\circ} \mathrm{C}$. Serum samples were analyzed to determine serum total cholesterol (TC), high-density lipoprotein cholesterol (HDL-C), low-density lipoprotein cholesterol (LDL-C), and triglyceride (TG) concentrations using a commercial kit (Biosino Biotechnology and Science, Beijing, China).

\section{Assay for Liver TC and TG}

After $4 \mathrm{wk}$ on the appropriate diet, all of the rats were euthanized. The livers were removed, rinsed with normal saline solution, blotted dry with filter paper and weighed. Liver TC and TG levels were determined according to the method of Chiu et al. (2006).

\section{Preparation of Samples for RNA Measurements}

After the 4-wk feeding period, rats were euthanized with diethyl ether. The small intestines were removed, flushed with ice-cold PBS, and cut into 3 sections of equal length. The sections were slit lengthwise, and the mucosas were gently scraped and frozen in liquid $\mathrm{N}_{2}$ and stored at $-80^{\circ} \mathrm{C}$. Total RNA was extracted from the tissue samples using RNA STAT-60 (Tel-Test, Friendswood, TX). Total protein was recovered from the organic phase that remained after RNA isolation by precipitating with isopropanol, washing with $0.3 \mathrm{M}$ of guanidine hydrochloride in $95 \%$ ethanol, and resuspending the protein pellet in $1 \%$ SDS and $50 \mathrm{mM}$ of Tris-HCl, pH 8.8 (Banerjee et al., 2003). The RNA concentration was determined by absorbance at $260 \mathrm{~nm}$, and the protein concentration was determined using the Bio-Rad Protein Assay Kit (Hercules, CA).

\section{Real-Time Quantitative PCR}

The RNA was prepared using a Qiagen RNeasy Mini Kit (Germantown, MD) according to the manufacturer's protocol, and cDNA was synthesized using the cDNA Synthesis Kit from Invitrogen (Carlsbad, CA), according to the manufacturer's protocol. Transcripts were detected using SYBR green-based (Applied Biosystems, Foster City, CA) real-time PCR. Forward and reverse primers were mixed in equal proportions and used at a final concentration of $0.2 \mathrm{mM}$. Human NPC1L1 (forward: 5'-TATGGTCGCCCGAAGCA-3', reverse: 5'-TGCGGTTGTTCTGGAAATACTG-3') and human $\beta$-actin (forward: 5'-CCTGGCACCCAGCACAAT-3', reverse: 5'-GCCGATCCACACGGAGTACT-3') transcripts were measured. Additionally, rat NPC1L1 (forward: 5'-AACAGCGAGAGGCTCACATT-3'; reverse: $5^{\prime}$-AGTGGCGTTCATGCCTGCCT-3') and rat $\beta$-actin (forward: 5'-ATTGTGATGGACTCCGGAGA-3'; reverse: 5'-CAGCTCATAGCTCTTCTCCA- $3^{\prime}$ ) transcripts were measured. $\beta$-Actin served as a housekeeping gene to normalize the expression of target genes. Relative expression was calculated according to the $2^{-\Delta \Delta \mathrm{Ct}}$ method as previously described (Livak and Schmittgen, 2001). Each experiment was performed with duplicate samples, and the mRNA levels of each sample were determined in triplicate. Real-time PCR was performed using the ABI 7500 System for data acquisition, and the data were analyzed using the ABI 7500 System Sequence Detection software (both from Applied Biosystems). The data are presented as mean values with standard deviations.

\section{Statistical Analysis}

Data are expressed as means with standard deviations. The statistical significance of the difference between 2 means was evaluated using a Student's $t$-test. For analyzing multiple mean values, Dunnett's test was used after an ANOVA. In these tests, values of $P<$ 0.05 were considered to be significant.

\section{RESULTS}

\section{Screening and Identification of Lactobacillus Isolates}

A total of 38 typical Lactobacillus isolates recovered from kefir grain samples on MRS plates were initially selected for screening. Typical colonies of these Lac- 
tobacillus isolates were randomly selected from MRS plates based on their morphological characteristics assessed by microscopic examination after Gram staining and from negative tests for the catalase reaction. For 12 of the isolates, a 250 bp fragment was amplified using 16S rRNA-based PCR primers specific for the genus Lactobacillus. Two standard probiotic cultures, Lb. acidophilus ATCC 4356 and Lb. plantarum ATCC 8014, were used as positive controls (data not shown) in the PCR assays.

Adherence of the putative probiotic organism to the gastrointestinal tract is crucial for the organism to have an extended residence time in the host. Therefore, the 12 isolates were subjected to an in vitro adherence test using the human carcinoma cell line Caco-2, which has been widely accepted as an in vitro model to assess the adhesion of potential probiotics to the intestinal epithelium. On qualitative evaluation, the isolate Lp27 most strongly adhered with Caco-2 cells and was selected for further characterization. The adhesion ratio of the Lp27 isolate to the Caco-2 cells was estimated to be 9.5 $\pm 2.5 \%$, which was comparable to the adhesion values of $6.8 \pm 1.2$ and $12.7 \pm 1.9 \%$ of $L b$. plantarum ATCC 8014 and Lb. acidophilus ATCC 4356, respectively, with Caco-2 cells. The $16 \mathrm{~S}$ rDNA gene sequencing identified the Lp27 as an Lb. plantarum species.

\section{Acid Tolerance}

The 4-h survival curve of the $\mathrm{Lp} 27$ isolate at $\mathrm{pH}$ values of 7.0, 3.0, 2.0, and 1.0 is shown in Figure 1A. The viability of Lp27 increased when it was incubated at $\mathrm{pH} 7.0$ and 3.0. As no viable count was observed after the fourth hour of incubation at $\mathrm{pH} 2.0$ and after the second hour at $\mathrm{pH} 1.0$, it was concluded that $\mathrm{Lp} 27$ could survive at $\mathrm{pH} 2.0$ for $3 \mathrm{~h}$ and $\mathrm{pH} 1.0$ for $1 \mathrm{~h}$. At $\mathrm{pH}$ 3.0, Lp27 remained viable for more than $4 \mathrm{~h}$.

\section{Bile Salt Tolerance}

As shown in Figure 1B, the time required to increase the A620 nm reading by 0.3 units was $4.0 \mathrm{~h}$ when Lp27 was incubated in MRS broth without oxgall, whereas the times required for this increase were 5.8 and $6.2 \mathrm{~h}$ when Lp27 was grown in MRS broth containing 0.2 and $0.3 \%$ oxgall, respectively. The lag phase in 0.2 and $0.3 \%$ oxgall concentration was 1.8 and $2.2 \mathrm{~h}$, respectively. Furthermore, no significant difference was observed between the lag times for the 2 oxgall concentrations. Maximum absorbance for Lp27 was acquired after 10 $\mathrm{h}$ in MRS broth without oxgall, whereas it required 11 and $14 \mathrm{~h}$ in MRS broth with 0.2 and $0.3 \%$ oxgall, respectively. However, the maximum value for absorbance at $620 \mathrm{~nm}$ was nearly the same for all treatments.

\section{Antibiotic Susceptibility}

The Lp27 isolate was found to be sensitive to tetracycline, erythromycin, chloramphenicol, and gentamicin, and resistant to vancomycin (MIC of $23 \mu \mathrm{g} / \mathrm{mL}$ ), according to the FEEDAP (2005) breakpoint (vancomycin, $4 \mu \mathrm{g} / \mathrm{mL}$; data not shown).

\section{Lp27 Inhibits NPC1L1 Expression in Caco-2 Cells}

The colon carcinoma cell line Caco-2 was used to elucidate the effects of probiotics on NPC1L1 expression in colonocytes. Cells were stimulated for $6 \mathrm{~h}$ with Lp27, Lb. plantarum ATCC 8014, or Lb. acidophilus ATCC 4356 (Figure 2A). The Lp27 isolate significantly downregulated the expression of NPC1L1 mRNA; $L b$. plantarum ATCC 8014 and Lb. acidophilus ATCC 4356
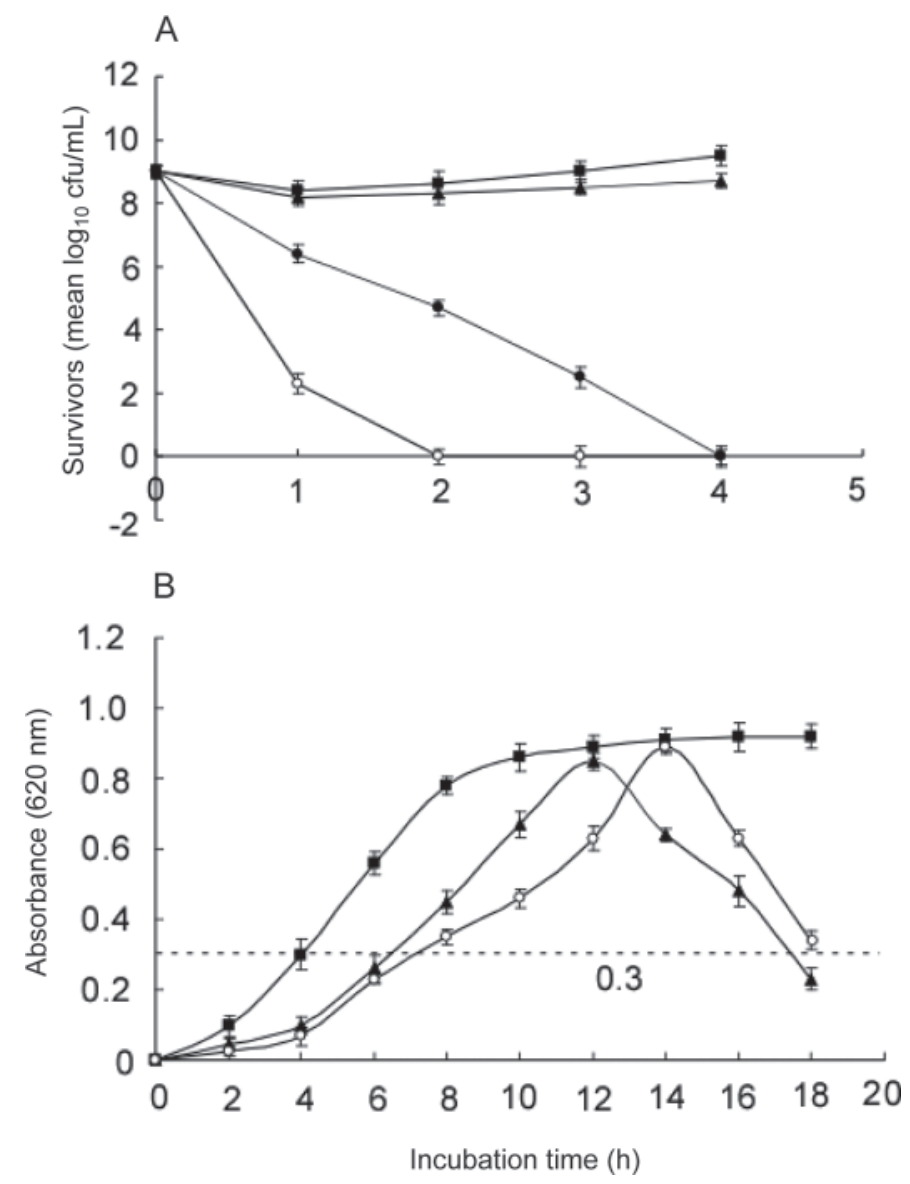

Figure 1. Survival curves of Lactobacillus plantarum Lp27 in media with different $\mathrm{pH}$ values (A) and growth curves in media with different bile salt concentrations (B). (A) Survival curve at $\mathrm{pH} 7.0$ (control; $\mathbf{\square})$, pH $3.0(\mathbf{\Delta}), \mathrm{pH} 2.0(\bullet)$, and $\mathrm{pH} 1.0(\mathrm{O})$. (B) Absorbance at $620 \mathrm{~nm}$ in de Man, Rogosa, Sharpe broth without bile salt (control; $\mathbf{\square})$, with $0.2 \%$ oxgall $(\mathbf{\Lambda})$, and $0.3 \%$ oxgall $(\bigcirc)$. Error bars represent standard deviations and each data point is the average of 3 repeated measurements from 2 independently replicated experiments $(\mathrm{n}=3)$. 
were also able to downregulate NPC1L1 mRNA. Further characterization of NPC1L1 expression revealed that Lp27 downregulated NPC1L1 mRNA in a doseand time-dependent manner (Figure 2B-C).

\section{Lp27 Decreases Micellar Cholesterol Uptake}

To address whether Lp27 interferes with the uptake of a micellar cholesterol solution, Caco-2 cells were incubated with Lp27, Lb. plantarum ATCC 8014, or Lb. acidophilus ATCC 4356 and were compared with an untreated control. One hour before harvesting the cells, $0.15 \mathrm{~mL}$ of a micellar solution was added to the medium, and the amount of cholesterol taken up by the cells was then measured (Figure 3). The uptake of cholesterol by cells incubated with Lp27 was approximately 1.5 -fold lower than the uptake of cholesterol by the untreated control. The cells incubated with $L b$. plantarum ATCC 8014 or Lb. acidophilus ATCC 4356 also exhibited decreased uptake of micellar cholesterol compared with the nontreated control.

\section{BW and Food Intake}

All rats appeared to be healthy throughout the feeding period. No significant differences were observed in BW gain, total food intake, or food intake efficiency $(P$ $>0.05$ ) between the 2 groups of rats (Table 1 ).

\section{Blood Lipid Analysis}

Table 2 shows the effects of dietary cholesterol and Lp27 on TC and TG levels in rats. The TC, LDL$\mathrm{C}$, and TG concentrations observed in the HC Lp27 group were significantly decreased compared with those observed in the HC diet group. However, the HDL$\mathrm{C}$ concentrations did not show a significant difference between the groups.

\section{Liver Lipid Analysis}

Table 3 shows the data for weight and lipid content of the rat livers. Average liver weight was not significantly different between the 2 groups. However, liver TC and TG concentrations were significantly lower in the $\mathrm{HC}$ Lp27 group than in the HC diet group $(P<0.05)$.

\section{Lp27 Inhibits NPC1L1 Expression in the Small Intestine}

To address the mechanism underlying Lp27-mediated inhibition of cholesterol absorption, mRNA levels of NPC1L1 in the small intestines were assayed (Figure 4). The level of NPC1L1 mRNA varied in different seg-
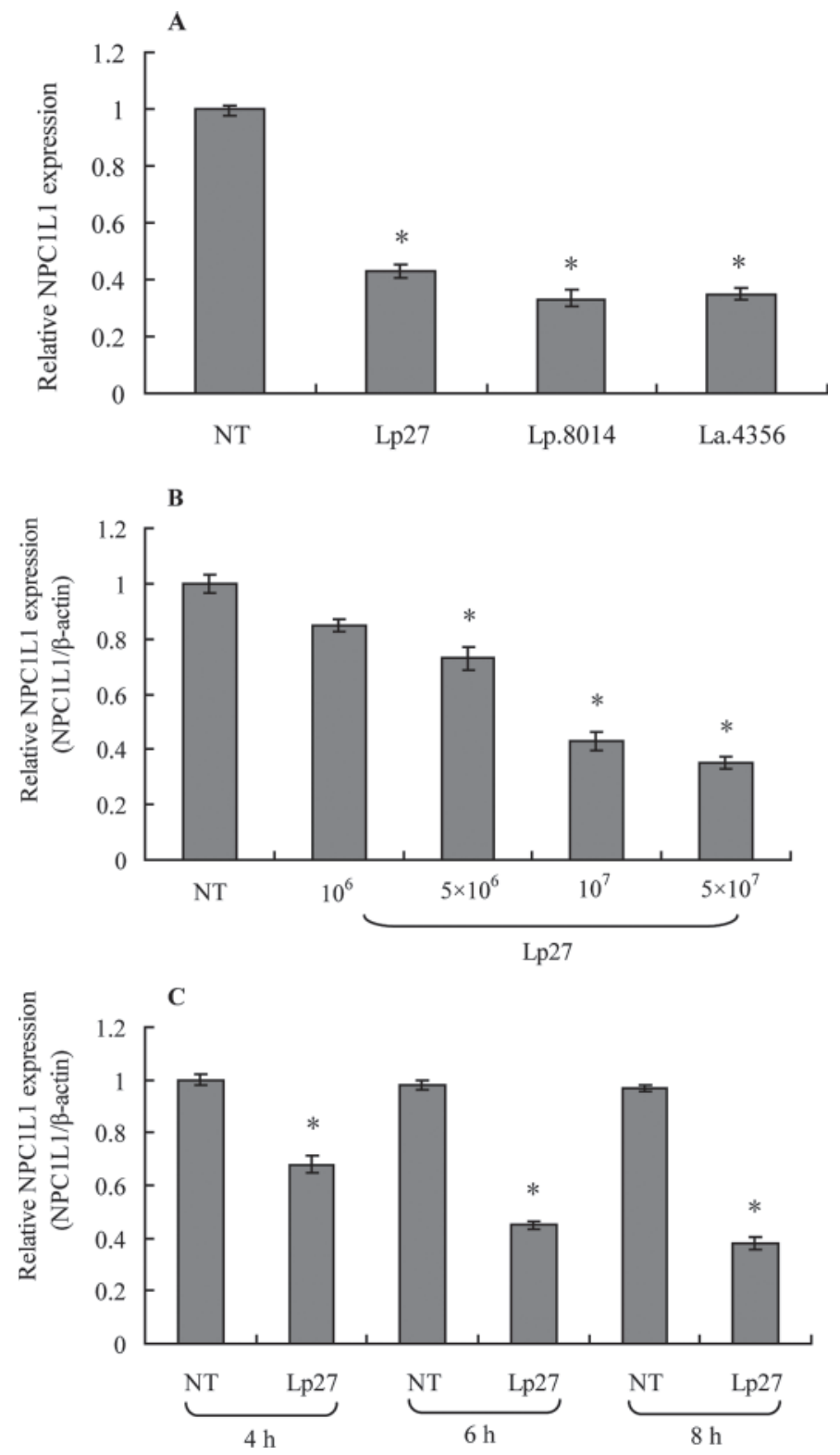

Figure 2. Probiotics can downregulate Niemann-Pick C1-like 1 (NPC1L1) expression in Caco-2 cells. (A) The expression of NPC1L1, as determined by real-time PCR, in Caco- 2 cells cocultured with Lp27, Lactobacillus plantarum ATCC 8014 (Lp.8014; 107 per mL) and Lactobacillus acidophilus ATCC 4356 (La.4356; $10^{7}$ per $\mathrm{mL}$ ) for $6 \mathrm{~h}$ was compared with the untreated (NT) control. The data are presented as the means and standard deviations. An asterisk represents standard error of $P<0.01$ compared with the NT control (by Dunnett's test for multiple comparisons). (B) Expression analysis of NPC1L1 in Caco-2 cells after $6 \mathrm{~h}$ of stimulation with $L b$. plantarum Lp27 at different concentrations. The data are presented as the means and SD. An asterisk represents a standard error of $P<0.01$ compared with the NT control (by a Dunnett's test for multiple comparisons). (C) Time course of the effects of $L b$. plantarum Lp27 (10 ${ }^{7}$ per $\left.\mathrm{mL}\right)$ on NPC1L1 mRNA expression in Caco-2 cells. The data are presented as the means and SD. An asterisk represents a standard error of $P<0.01$ compared with the NT control (by Student's $t$ test). 


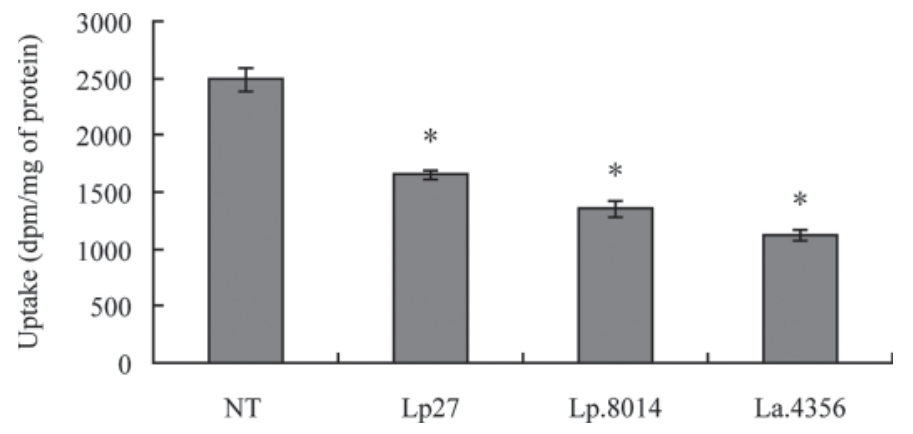

Figure 3. Lactobacillus plantarum Lp27 inhibits cholesterol uptake in Caco-2 cells. Caco-2 cells were cocultured with $L b$. plantarum ATCC 8014 (Lp.8014) and Lactobacillus acidophilus ATCC 4356 (La.4356) as well as the untreated (NT) control. One hour before harvesting the cells, the medium was supplemented with $0.15 \mathrm{~mL}$ of a micellar solution. At the end of the incubation, the cells were washed thoroughly, and cellular lipids were extracted. The radioactivity in the cellular lipid extract was measured. Values shown are the means and standard deviations of 3 independent experiments. Statistically significant differences versus NT were determined by Dunnett's test $(*=P<0.05)$.

ments of the rat intestine, with the peak expression observed in the proximal jejunum. In the duodenal and jejunal segments, NPC1L1 mRNA levels detected in the HC Lp27 group were significantly lower than those detected in the $\mathrm{HC}$ diet group. In contrast, no significant difference was observed in NPC1L1 mRNA levels in the ileal segment.

\section{DISCUSSION}

To survive passage through the stomach, probiotic bacteria must be tolerant of acidic environments. Stresses to ingested microorganisms begin in the stomach, which has a $\mathrm{pH}$ between 1.5 and 3 , and continue in the upper intestine, which contains a 0.03 to $0.3 \%$ (wt/ vol) concentration of bile salts. For probiotic strains, survival at $\mathrm{pH} 3$ for $2 \mathrm{~h}$ and in a bile concentration of $0.3 \%$ (wt/vol) for $12 \mathrm{~h}$ is considered optimal (Usman and Hosono, 1999). The Lp27 isolate survived at pH 3
Table 1. Body weight gain, total food intake, and food intake efficiency of rats fed a high-cholesterol (HC) diet for $4 \mathrm{wk}^{1}$

\begin{tabular}{lcc}
\hline Item & HC diet $^{2}$ & HC Lp2 $7^{3}$ \\
\hline Body weight gain $(\mathrm{g})$ & $120.04 \pm 2.89^{\mathrm{a}}$ & $118.52 \pm 3.12^{\mathrm{a}}$ \\
Total food intake $(\mathrm{g})$ & $589.76 \pm 21.04^{\mathrm{a}}$ & $597.37 \pm 17.21^{\mathrm{a}}$ \\
Food efficiency ${ }^{\mathrm{a}}(\%)$ & $20.35 \pm 0.37^{\mathrm{a}}$ & $19.51 \pm 0.42^{\mathrm{a}}$ \\
\hline${ }^{\mathrm{a} M e a n}$ values within a row with different superscripted letters differ \\
significantly $(P<0.05)$. \\
${ }^{1}$ The data are shown as the mean $\pm \mathrm{SD}$. \\
${ }^{2} \mathrm{HC}$ diet group $=$ high-cholesterol diet. \\
${ }^{3} \mathrm{HC}$ Lp27 group $=$ high-cholesterol diet + Lactobacillus plantarum \\
Lp27.
\end{tabular}

${ }^{4}$ Food efficiency $(\%)=(B W$ gain $/$ food intake $) \times 100$.

for $2 \mathrm{~h}$ and even grew well in $0.3 \%$ oxgall; thus, Lp27 exhibited good acid and bile salt tolerance.

One of the required properties of probiotic strains is that they are safe for human consumption. A qualified presumption of safety status has been granted to several Lactobacillus species; Lb. plantarum is included in the list of taxonomic units within the qualified presumption of safety status, provided that the lack of acquired antibiotic resistance is systematically demonstrated (EFSA, 2007). The Lp27 strain was tested for susceptibility to 5 antibiotics belonging to the clinically most relevant antibiotics. The antibiotic susceptibility tests indicated that Lp27 was only resistant to vancomycin. The results were as expected, as lactobacilli are known to be naturally resistant toward vancomycin and such resistance is usually intrinsic, chromosomally encoded, and not transmissible (Klein et al., 1998, 2000).

High levels of serum cholesterol have been associated with an increased risk of coronary heart disease. The use of probiotic bacteria to reduce serum cholesterol levels has attracted much interest in recent years (Ebringer et al., 2008). The results of the present study indicate that Lp27 was able to reduce cholesterol absorption by inhibiting NPC1L1 gene expression in Caco-2 cells. Our previous in vitro study indicated that $L b$. acidophilus

Table 2. Serum total cholesterol (TC), low-density lipoprotein-cholesterol (LDL-C), and triglycerides (TG) levels in rats fed experimental diets ${ }^{1}$

\begin{tabular}{|c|c|c|c|c|c|}
\hline Item $^{2}$ & Day 0 & Day 7 & Day 14 & Day 21 & Day 28 \\
\hline \multicolumn{6}{|l|}{$\mathrm{TC}(\mathrm{mg} / \mathrm{L})$} \\
\hline HC-diet & $986.18 \pm 14.5^{\mathrm{a}}$ & $996.46 \pm 21.3^{\mathrm{a}}$ & $1,089.32 \pm 31.2^{\mathrm{a}}$ & $1,187.36 \pm 26.9^{\mathrm{a}}$ & $1,269.18 \pm 31.53^{\mathrm{a}}$ \\
\hline \multicolumn{6}{|c|}{ LDL-C (mg/L) } \\
\hline HC-diet & $278.21 \pm 18.20^{\mathrm{a}}$ & $325.32 \pm 17.26^{\mathrm{a}}$ & $493.46 \pm 12.48^{\mathrm{a}}$ & $586.59 \pm 16.63^{\mathrm{a}}$ & $687.24 \pm 21.32^{\mathrm{a}}$ \\
\hline HC-Lp27 & $283.64 \pm 15.38^{\mathrm{a}}$ & $278.47 \pm 13.52^{\mathrm{a}}$ & $256.25 \pm 16.52^{\mathrm{b}}$ & $245.37 \pm 15.58^{\mathrm{b}}$ & $223.31 \pm 18.03^{\mathrm{b}}$ \\
\hline \multicolumn{6}{|l|}{ TG $(\mathrm{mg} / \mathrm{L})$} \\
\hline
\end{tabular}

\footnotetext{
${ }^{\mathrm{a}, \mathrm{b}}$ Mean values within the same column followed by different superscript letters are significantly different $(P<0.05)$.

${ }^{1}$ The data are shown as the mean $\pm \mathrm{SD}$.

${ }^{2} \mathrm{HC}$ diet group $=$ high-cholesterol diet; HC Lp27 group = high-cholesterol diet + Lactobacillus plantarum Lp27.
} 
Table 3. Liver cholesterol and triglycerides (TG) levels in rats fed experimental $\operatorname{diets}^{1}$

\begin{tabular}{|c|c|c|c|}
\hline $\begin{array}{l}\text { Treatment } \\
\text { group }\end{array}$ & $\begin{array}{c}\text { Liver } \\
\text { weight }(\mathrm{g})\end{array}$ & $\begin{array}{c}\text { Liver } \\
\text { cholesterol }(\mathrm{mg} / \mathrm{g})\end{array}$ & $\begin{array}{l}\text { Liver TG } \\
(\mathrm{mg} / \mathrm{g})\end{array}$ \\
\hline $\begin{array}{l}\text { HC-diet } \\
\text { HC-Lp } 27^{3}\end{array}$ & $\begin{array}{l}9.08 \pm 0.18^{\mathrm{a}} \\
9.06 \pm 0.11^{\mathrm{a}}\end{array}$ & $\begin{array}{r}12.52 \pm 0.23^{\mathrm{a}} \\
8.25 \pm 0.12^{\mathrm{b}}\end{array}$ & $\begin{array}{l}36.28 \pm 0.27^{\mathrm{a}} \\
25.16 \pm 0.17^{\mathrm{b}}\end{array}$ \\
\hline \multicolumn{4}{|c|}{$\begin{array}{l}\overline{\mathrm{a}, \mathrm{b}} \text { Mean values within the same column followed by different superscript letters are significantly different }(P \\
<0.05) \text {. }\end{array}$} \\
\hline
\end{tabular}

4356 reduces cholesterol absorption by downregulating the expression of NPC1L1 (Huang and Zheng, 2010). Substantial downregulation of NPC1L1 expression in Caco-2 cells by Lactobacillus rhamnosus BFE5264 and Lb. plantarum has also been reported by Yoon et al. (2013). These results indicate that downregulation of NPC1L1 might be an activity of most Lactobacillus strains and may provide a possible molecular mechanism for the modulation of cholesterol concentrations. Moreover, Lp27 reduced the serum TC, LDL-C, and TG concentrations of rats fed a high-cholesterol diet, as reported earlier for other $L b$. plantarum strains (Nguyen et al., 2007; Fazeli et al., 2010). No significant differences in HDL-C concentrations were observed in our study, which is in agreement with previous results in rats and human subjects (Abd El-Gawad et al., 2005; Wang et al., 2009). Significant reductions in TC and TG concentrations were also observed in the livers of rats in the Lp27-fed group. These findings demonstrated that the serum TC and TG levels in HC Lp27 group were actually reduced rather than merely being redistributed from the blood to the liver.

Because cholesterol absorption primarily occurs in the duodenum and proximal jejunum, with little absorption by the ileal segment of the intestine (Borgstrom, 1960; Grundy, 1983), we investigated NPC1L1 mRNA expression along the duodenum-ileum axis. The level of NPC1L1 mRNA varied in the different segments of rat intestine, with the peak expression detected in the proximal jejunum; this result is in agreement with a

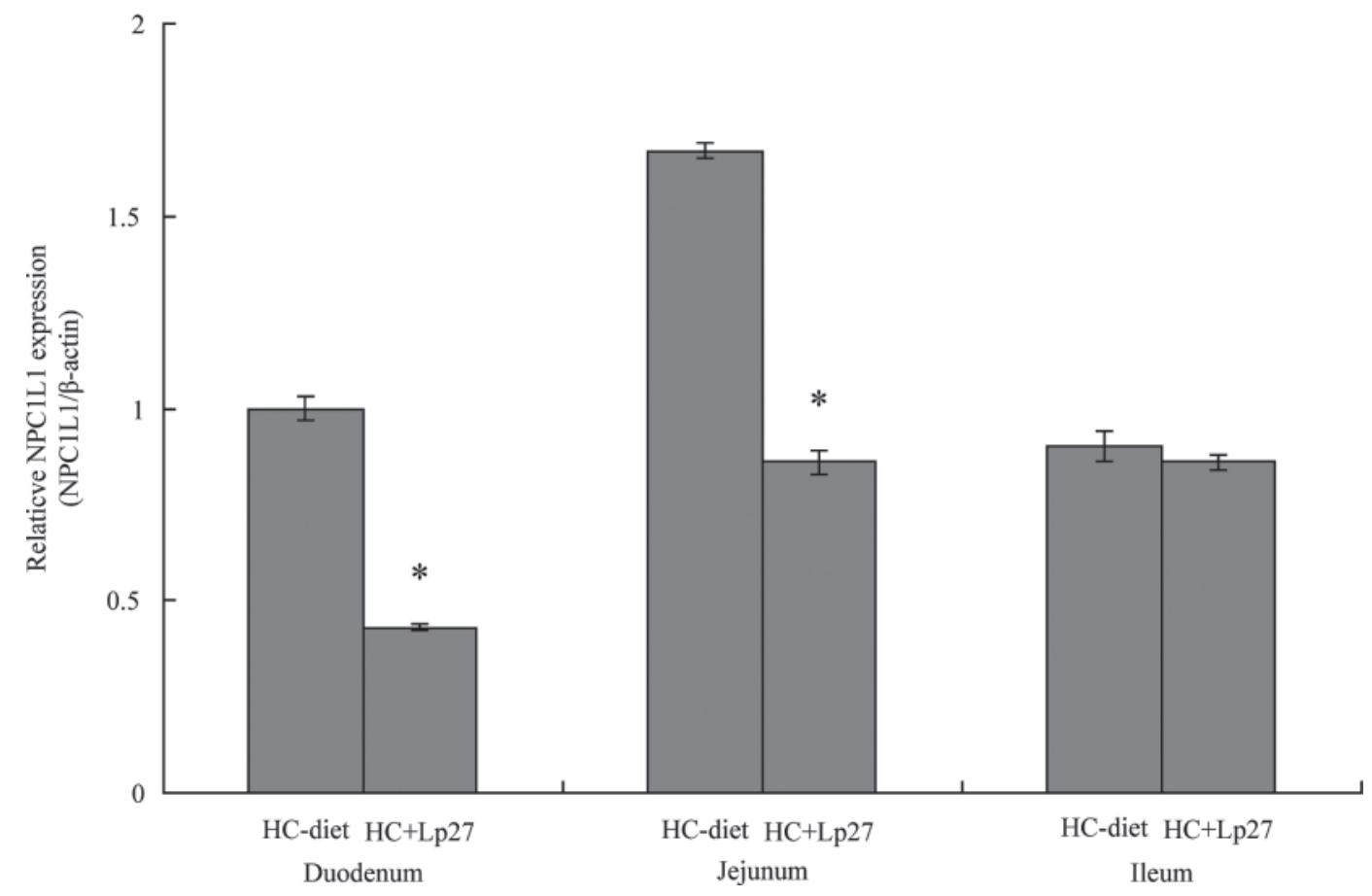

Figure 4. Real-time PCR of Niemann-Pick C1-like 1 (NPC1L1) mRNA in the small intestines of rats fed Lactobacillus plantarum Lp27 was compared with NPC1L1 mRNA levels in the small intestines of the control group [high-cholesterol (HC) diet group]. The data are presented as the means and standard deviations. An asterisk represents mean values that differed significantly compared with the control group by Student's $t$ test $(P<0.05)$. 
study by Altmann et al. (2004). Moreover, NPC1L1 mRNA levels in the duodenal and jejuna segments of rats in the Lp27-fed group were significantly lower than those in the duodenal and jejunal segments of the control group. The present results indicate that Lp27 is able to reduce cholesterol absorption by inhibiting NPC1L1 mRNA transcription in the small intestine, which is in agreement with our previous results (Huang et al., 2010).

\section{CONCLUSIONS}

In summary, Lb. plantarum Lp27 isolated from TK exhibited efficient cholesterol-reducing ability in vitro and in vivo. The results of this study indicate that the probiotic potential of the Lp27 strain for the control of cholesterol is at least partially mediated by the downregulation of NPC1L1. Furthermore, these results indicate a possible mechanism for the cholesterolreducing effects of probiotics. In future studies it will be necessary to test more animals, using varying doses of bacteria over long durations, to assess the long-term probiotic potential of Lp27.

\section{ACKNOWLEDGMENTS}

This work was supported by the National Natural Science Foundation of China (Changchun; No. 31100022) and the Program of Science and Technology Development Plan of Jilin Province (Changchun; No. 20110737).

\section{REFERENCES}

Abd El-Gawad, I. A., E. M. El-Sayed, S. A. Hafez, H. M. El-Zeinia, and F. A. Salehb. 2005. The hypocholesterolaemic effect of milk yoghurt and soy-yoghurt containing bifidobacteria in rats fed on a cholesterol-enriched diet. Int. Dairy J. 15:37-44.

Altmann, S. W., H. R. Jr. Davis, L. J. Zhu, X. Yao, L. M. Hoos, G. Tetzloff, S. P. Iyer, M. Maguire, A. Golovko, M. Zeng, L. Wang, N. Murgolo, and M. P. Graziano. 2004. Niemann-Pick C1 like 1 protein is critical for intestinal cholesterol absorption. Science 303:1201-1204.

Angulo, L., E. Lopez, and C. Lema. 1993. Microflora present in kefir grains of the Galician region (north-west of Spain). J. Dairy Res. 60:263-267.

Banerjee, S., A. Smallwood, A. E. Chambers, and K. Nicolaides. 2003. Quantitative recovery of immunoreactive proteins from clinical samples following RNA and DNA isolation. Biotechniques 35:450-452., 454, 456.

Borgstrom, B. 1960. Studies on intestinal cholesterol absorption in the human. J. Clin. Invest. 39:809-815.

Chen, Y. P., P. J. Hsiao, W. S. Hong, T. Y. Dai, and M. J. Chen. 2012. Lactobacillus kefiranofaciens M1 isolated from milk kefir grains ameliorates experimental colitis in vitro and in vivo. J. Dairy Sci. 95:63-74.

Chiu, C. H., T. Y. Lu, Y. Y. Tseng, and T. M. Pan. 2006. The effects of Lactobacillus-fermented milk on lipid metabolism in hamsters fed on high-cholesterol diet. Appl. Microbiol. Biotechnol. 71:238-245.
Davis, H. R. Jr., L. M. Hoos, G. Tetzloff, M. Maguire, L. J. Zhu, M. P. Graziano, and S. W. Altmann. 2007. Deficiency of Niemann-Pick $\mathrm{C} 1$ like 1 prevents atherosclerosis in ApoE -/- mice. Arterioscler. Thromb. Vasc. Biol. 27:841-849.

Davis, H. R. Jr., L. J. Zhu, L. M. Hoos, G. Tetzloff, M. Maguire, J. Liu, X. Yao, S. P. Iyer, M. H. Lam, E. G. Lund, P. A. Detmers, M. P. Graziano, and S. W. Altmann. 2004. Niemann-Pick C1 Like 1 (NPC1L1) is the intestinal phytosterol and cholesterol transporter and a key modulator of whole-body cholesterol homeostasis. J. Biol. Chem. 279:33586-33592.

Diniz, R. O., L. K. Garla, J. M. Schneedorf, and J. C. T. Carvalho. 2003. Study of anti-inflammatory activity of Tibetan mushroom, a symbiotic culture of bacteria and fungi encapsulated into a polysaccharide matrix. Pharmacol. Res. 47:49-52.

Dubernet, S., N. Desmasures, and M. Gueguen. 2002. A PCR-based method for identification of lactobacilli at the genus level. FEMS Microbiol. Lett. 214:271-275.

Ebringer, L., M. Ferencik, and J. Krajcovic. 2008. Beneficial health effects of milk and fermented dairy products-Review. Folia Microbiol. (Praha) 53:378-394.

European Food Safety Authority. 2007. Introduction of a qualified presumption of safety (QPS) approach for assessment of selected microorganisms referred to EFSA. EFSA J. 587:1-16.

Farnworth, E. R., and I. Mainville. 2003. Kefir: A fermented milk product. Pages 77-111 in Handbook of Fermented Functional Foods. CRC Press, Boca Press, Boca Raton, FL.

Fazeli, H., J. Moshtaghian, M. Mirlohi, and M. Shirzadi. 2010. Reduction in serum lipid parameters by incorporation of a native strain of Lactobacillus plantarum A7 in mice. Iran. J. Diabetes Lipid Disord. 9:1-7.

FEEDAP. 2005. Opinion of the scientific panel on additives and products or substances used in animal feed on the updating of the criteria used in the assessment of bacteria for resistance to antibiotics of human or veterinary importance. EFSA J. 223:1-12.

Franz, C. M. A. P., G. Y. Cho, and W. H. Holzapfel. 2010. Probiotics: Taxonomy and technological features. Pages 241-245 in Probiotic and Prebiotic Foods: Technology, Stability and Benefits to Human. N. P. Shah, A. G. da Cruz, and J. de Assis Fonseca Faria, ed. Nova Science Publishers, Hauppauge, NY

Garrote, G. L., A. G. Abraham, and G. L. de Antoni. 2001. Chemical and microbiological characterization of kefir grains. J. Dairy Res. 68:639-652.

Grundy, S. M. 1983. Absorption and metabolism of dietary cholesterol. Annu. Rev. Nutr. 3:71-96.

Huang, Y., J. Wang, Y. Cheng, and Y. Zheng. 2010. The hypocholesterolaemic effects of Lactobacillus acidophilus American Type culture collection 4356 in rats are mediated by the down-regulation of Niemann-Pick C1-like 1. Br. J. Nutr. 104:807-812.

Huang, Y., and Y. Zheng. 2010. The probiotic Lactobacillus acidophilus reduces cholesterol absorption through the down-regulation of Niemann-Pick C1-like 1 in Caco-2 cells. Br. J. Nutr. 103:473-478.

Jacobsen, C. N., V. Rosenfeldt Nielsen, A. E. Hayford, P. L. Moller, K. F. Michaelsen, A. Paerregaard, B. Sandstrom, M. Tvede, and M. Jakobsen. 1999. Screening of probiotic activities of forty-seven strains of Lactobacillus spp. by in vitro techniques and evaluation of the colonization ability of five selected strains in humans. Appl. Environ. Microbiol. 65:4949-4956.

Klein, G., C. Hallmann, I. A. Casas, J. Abad, J. Louwers, and G. Reuter. 2000. Exclusion of vanA, vanB and vanC type glycopeptides resistance in strains of Lactobacillus reuteri and Lactobacillus rhamnosus used as probiotics by polymerase chain reaction and hybridization methods. J. Appl. Microbiol. 89:815-824.

Klein, G., A. Pack, C. Bonaparte, and G. Reuter. 1998. Taxonomy and physiology of probiotic lactic acid bacteria. Int. J. Food Microbiol. 41:103-125.

Liong, M. T., and N. P. Shah. 2005. Acid and bile tolerance and cholesterol removal ability of lactobacilli strains. J. Dairy Sci. $88: 55-66$.

Liong, M. T., and N. P. Shah. 2006. Effects of a Lactobacillus casei symbiotic on serum lipoprotein, intestinal microflora, and organic acids in rats. J. Dairy Sci. 89:1390-1399. 
Liu, J. R., S. Y. Wang, M. J. Chen, H. L. Chen, P. Y. Yueh, and C. W. Lin. 2006. Hypocholesterolaemic effects of milk-kefir and soyamilkkefir in cholesterol-fed hamsters. Br. J. Nutr. 95:939-946.

Livak, K. J., and T. D. Schmittgen. 2001. Analysis of relative gene expression data using real-time quantitative PCR and the 2(-Delta Delta C (T)) method. Methods 25:402-408.

Manson, J. E., H. Tosteson, P. M. Ridker, S. Satterfield, P. Hebert, G. T. O'Connor, J. E. Buring, and C. H. Hennekens. 1992. The primary prevention of myocardial infarction. N. Engl. J. Med. 326:1406-1416.

Nguyen, T. D., J. H. Kang, and M. S. Lee. 2007. Characterization of Lactobacillus plantarum $\mathrm{PH} 04$, a potential probiotic bacterium with cholesterol-lowering effects. Int. J. Food Microbiol. 113:358 361.

Ooi, L. G., and M. T. Liong. 2010. Cholesterol-lowering effects of probiotics and prebiotics: A review of in vivo and in vitro findings. Int. J. Mol. Sci. 11:2499-2522.

Pospiech, A., and B. Neumann. 1995. A versatile quick preparation of genomic DNA from Gram-positive bacteria. Trends Genet. 11:217-218.

Rossetti, L., D. Carminati, M. Zago, and G. Giraffa. 2009. A qualified presumption of safety approach for the safety assessment of Grana Padano whey starters. Int. J. Food Microbiol. 130:70-73.

Silva, K. R., S. A. Rodrigues, L. Xavier, and A. S. Lima. 2009. Antimicrobial activity of broth fermented with kefir grains. Appl. Biochem. Biotechnol. 152:316-325.

Temel, R. E., J. K. Sawyer, L. Yu, C. Lord, C. Degirolamo, A. McDaniel, S. Marshall, N. Wang, R. Shah, L. L. Rudel, and J. M. Brown. 2010. Biliary sterol secretion is not required for macrophage reverse cholesterol transport. Cell Metab. 12:96-102.

Temel, R. E., W. Tang, Y. Ma, L. L. Rudel, M. C. Willingham, Y. A. Ioannou, J. P. Davies, L. M. Nilsson, and L. Yu. 2007. Hepatic
Niemann-Pick C1-like 1 regulates biliary cholesterol concentrations and is a target of ezetimibe. J. Clin. Invest. 117:1968-1978.

Urdaneta, E., J. Barrenetxe, P. Aranguren, A. Irigoyen, F. Marzo, and F. C. Ibanez. 2007. Intestinal beneficial effects of kefir-supplemented diet in rats. Nutr. Res. 27:653-658.

Usman, , and A. Hosono. 1999. Bile tolerance, taurocholate deconjugation, and binding of cholesterol by Lactobacillus gasseri strains. J. Dairy Sci. 82:243-248.

Vinderola, C. G., J. Duarte, D. Thangavel, G. Perdigon, E. Farnworth, and C. Matar. 2005. Immunomodulating capacity of kefir. J. Dairy Res. 72:195-202.

Wang, Y., N. Xu, A. Xi, Z. Ahmed, B. Zhang, and X. Bai. 2009. Effects of Lactobacillus plantarum MA2 isolated from Tibet kefir on lipid metabolism and intestinal microflora of rats fed on highcholesterol diet. Appl. Microbiol. Biotechnol. 84:341-347.

Weisburg, W. G., S. M. Barns, D. A. Pelletier, and D. Lane. 1991. 16S ribosomal DNA amplification for phylogenetic study. J. Bacteriol. 173:697-703.

Wilson, M. D., and L. L. Rudel. 1994. Review of cholesterol absorption with emphasis on dietary and biliary cholesterol. J. Lipid Res. 35:943-955.

Yin, Y. N., Q. F. Yu, N. Fu, X. W. Liu, and F. G. Lu. 2010. Effects of four bifidobacteria on obesity in high-fat diet induced rats. World J. Gastroenterol. 16:3394-3401.

Yoon, H. S., J. H. Ju, H. N. Kim, H. J. Park, Y. Ji, J. E. Lee, H. K. Shin, M. S. Do, and W. Holzapfel. 2013. Reduction in cholesterol absorption in Caco-2 cells through the down-regulation of Niemann-Pick C1-like 1 by the putative probiotic strains Lactobacillus rhamnosus BFE5264 and Lactobacillus plantarum NR74 from fermented foods. Int. J. Food Sci. Nutr. 64:44-52. 